\title{
Impact of carbon nanotubes addition on electrical, thermal, morphological, and tensile properties of poly (ethylene terephthalate)
}

\author{
Basheer A. Alshammari ${ }^{1} \cdot$ Arthur Wilkinson $^{2}$
}

Received: 21 March 2016/ Accepted: 2 June 2016/Published online: 16 June 2016

(c) The Author(s) 2016. This article is published with open access at Springerlink.com

\begin{abstract}
In this study, multi-walled carbon nanotubes (MWCNTs) were incorporated into poly (ethylene terephthalate) (PET) matrix in their as-received (A-MWCNTs) and treated (T-MWCNTs) forms. Melt-compounding method was used for the preparation of these carbon nanotubes (CNTs)-reinforced PET composites. The electrical conductivity, thermal stability, morphological, and tensile properties were investigated. For testing and characterization, impedance spectroscopy, thermo-gravimetric analysis, scanning electron microscopy, transmission electron microscopy, Fourier-transform infrared spectroscopy and tensile testing were utilized. The results demonstrates that an incorporation of $\sim 0.25 \mathrm{wt} \%$ A-MWCNTs, an electrically conductive polymer nanocomposite $(\sim 0.2 \mathrm{~S} / \mathrm{m})$, was formed with a low percolation threshold $(\sim 0.33 \mathrm{wt} \%)$. In contrast, at the same loading of T-MWCNTs or even up $2 \mathrm{wt} \%$ did not yield conductive polymer. Presumably, such behavior is attributed to the acid treatment that disrupted the inherent electrical conductivity of the CNTs and also reduced their aspect ratio. Nevertheless, T-MWCNTs showed a better dispersion and distribution into the PET matrix than that of A-MWCNTs counterpart. Moreover, an improved tensile behavior was observed for T-MWCNTs incorporated composites than that of A-MWCNTs counterpart. Improved thermal stability was observed for PET/
\end{abstract}

Basheer A. Alshammari

bshammari@kacst.edu.sa; b_shammari@hotmail.com

1 Petrochemical Research Institute, King Abdulaziz City for Science and Technology, P.O. Box 6086, Riyadh 11442, Saudi Arabia

2 Materials Science Centre and North West Composites Centre, School of Materials, The University of Manchester, Grosvenor Street, Manchester M13 9PL, UK
A-MWCNTs in both the air and nitrogen atmospheres. Whereas, PET/T-MWCNTs exhibited the highest thermal stability in all samples in nitrogen atmosphere. However, poor thermal response was seen in air atmosphere.

Keywords Carbon nanotubes · PET · Nanocomposites · Modifications and properties

\section{Introduction}

Carbon nanotubes (CNTs) are one of the most conductive carbon allotropies that have been discovered by Sumio Iijima in 1991. There are various types of CNTs based on the carbon layers in their sidewalls, such as single-walled carbon nanotubes, two concentric layers known as doublewalled carbon nanotubes and multiple concentric layers or multi-walled carbon nanotubes (MWCNTs). The distance between two carbon layers in the sidewall of CNTs is $0.34 \mathrm{~nm}$. These CNTs have attracted considerable amount of research due to their exceptional properties and outstanding aspect ratio (its aspect ratio $>1000$ ) in comparison with the traditional conductive carbon fillers, such as carbon black and graphite [1-4], for instance, tensile modulus of $\sim 1 \mathrm{TPa}$, strength of 10-60 GPA, outstanding thermal stability in the air $\left(\sim 700^{\circ} \mathrm{C}\right)$, and electrical resistivity of $\sim 50 \mu \Omega \mathrm{cm}[4,5]$.

These exceptional properties make CNTs potential reinforcement materials for polymer matrices to produce high-performance polymer nanocomposites and, in particular, conductive polymer composites (CPCs). Even if the price of CNTs is reducing over years, it is still costly than that of the traditional carbon fillers. Therefore, to minimize the cost of the finished products, reduced electrical percolation threshold ( $\Phi$ ) value is highly desired. The $\Phi$ value 
is the critical loading or concentration of a conductive filler at which the electrical conductivity of polymer composite increases by several orders magnitude. This is because it exhibits transition from insulating to the semi-conductive or conductive composites. Another advantage of lower $\Phi$ is an improved process-ability and enhanced mechanical properties, since high filler loading may induce or generate more stress concentrators $[6,7]$. In this investigation, $\Phi$ was obtained by fitting the experimental data to the percolation theory.

To reduce the value of $\Phi$, good dispersion of CNTs filler into polymer matrix is needed. Nevertheless, due to significant lengths of CNTs that causes entanglement and large surface area-to-volume ratio associated with van der Waals forces of attraction between the tubes leading agglomerations of CNTs into the polymer matrix. As a result, poor interfacial adhesion, insufficient dispersion, and non-uniform distribution are observed. To solve these problems, chemical modification or functionalisation of CNTs, such as acid treatment, was suggested by several researchers $[6,8]$. Nonetheless, at same time, such treatments were reported to be deleterious for electrical response of CNTs. This was due to change in hybridization from $\mathrm{sp}^{2}$ to $\mathrm{sp}^{3}$ [2].

Furthermore, there are three frequently adopted methods for the production of composites; in situ polymerization, solution, and melt compounding. Out of these methods, the melt compounding is an environmentally friendly technique $[2,5,6]$. Therefore, it was used for producing PETCNTs nanocomposites in this study. Furthermore, poly (ethylene terephthalate) (PET) is a thermoplastic semicrystalline polymer used commonly in textile fibers, films, etc. This is due to its good strength, low melt viscosity, chemical resistance, and stability of dimensions [9, 10]. Nevertheless, an enhancement in electrical conductivity is required for electrostatic/electromagnetic dissipations applications [11]. To circumvent electrostatic charging of an insulating matrix, an electrical conductivity above $\sigma=10^{-6} \mathrm{~S} / \mathrm{m}$ is required $[12,13]$. An additional exciting application of PET-CNTs nanocomposites is the replacement of indium tin oxide electrodes [14]. In this study, asreceived MWCNTs (A-MWCNTs) and acid-treated multiwall carbon nanotubes (T-MWCNTs) were used. Usually, acid treatment is believed to improve dispersion and adhesion of CNTs. Therefore, PET was compounded with A-MWCNTs and T-MWCNT as to investigate the electrical, morphological, thermal, and tensile properties of resultant composites. Thus, the focus of this investigation is to develop a systematic baseline for all above properties under similar experimental conditions, in addition to understand the influence of functionalization treatment on CNTs and resultant composites.

\section{Experiment}

\section{Materials}

PET was received in the form of resin and it purchased from Equipolymers (grade: LIGHTER C93). Table 1 shows some of its properties provided by the supplier.

MWCNTs were supplied by Nanocyl (grade: Nanocy7000 ) having $9.5 \mathrm{~nm}$ and $\sim 1.5 \mu \mathrm{m}$ average diameter and length, respectively. Sulfuric and nitric acids were purchased from Sigma-Aldrich with concentrations of 98 and $70 \%$, respectively.

\section{CNTs modification}

According to acid modification technique [15], $1 \mathrm{~g}$ of the A-MWCNTs was added to $40 \mathrm{~mL}$ of the acid mixture in a round-bottomed flask. Therefore, as-received CNTs or A-MWCNTs were immersed into the mixture of $\mathrm{HNO}_{3}$ and $\mathrm{H}_{2} \mathrm{SO}_{4}$ in a 1:3 ratio, respectively. The mixture refluxed at $120{ }^{\circ} \mathrm{C}$ for $30 \mathrm{~min}$. Then, the mixture cooled and washed with distilled water until neutral $\mathrm{pH}$ was obtained $(\mathrm{pH} \sim 7)$. This was followed by filtration step via a polypropylene membrane filter $(0.2 \mu \mathrm{m}$ pore size $)$ to recover the treated MWCNTs (T-MWCNTs) from the mixture. The process schematic is shown in Fig. 1.

\section{Preparation of nanocomposites}

PET matrix and CNTs (A-MWCNTs and T-MWCNTs) were dried in vacuum oven at $120^{\circ} \mathrm{C}$ overnight before melt compounding was carried out. The preparation of the nanocomposites was carried out using a laboratory scale extruder (Thermo-Haake Minilab, capacity: $7 \mathrm{~cm}^{3}$ ) equipped with co-rotating twin-screws. The mixing time, temperature, and screw speed were set at $5 \mathrm{~min}, 280^{\circ} \mathrm{C}$, and $45 \mathrm{rpm}$, respectively. The extruded samples were compression moulded at $280^{\circ} \mathrm{C}$ for $10 \mathrm{~min}$ and quenched in an ice bath as to reduce the crystallinity and enhance ductility for easy sampling. Extruded samples were also injection moulded using a Haake Minijet II injection-moulding machine as to obtain the dumbbell shape specimens for the tensile test (at $400 \mathrm{MPa}$ ). For this purpose, the injection cylinder and the mould were preheated to 280 and $60{ }^{\circ} \mathrm{C}$, respectively.

\section{Characterization of nanocomposites}

\section{Morphology characterization}

The CNTs and nanocomposites samples were characterized using an SEM (Philips XL30) at an accelerating 
Table 1 Properties of PET matrix

\begin{tabular}{lll}
\hline Properties & Values & Unit \\
\hline $\begin{array}{l}\text { Intrinsic } \\
\text { viscosity }\end{array}$ & 0.80 & $\mathrm{dl} / \mathrm{g}$ \\
Glass transition & 78 & \\
Melting point & 247 & ${ }^{\circ} \mathrm{C}$ \\
Bulk density & 0.88 & ${ }^{\circ} \mathrm{C}$ \\
\hline
\end{tabular}

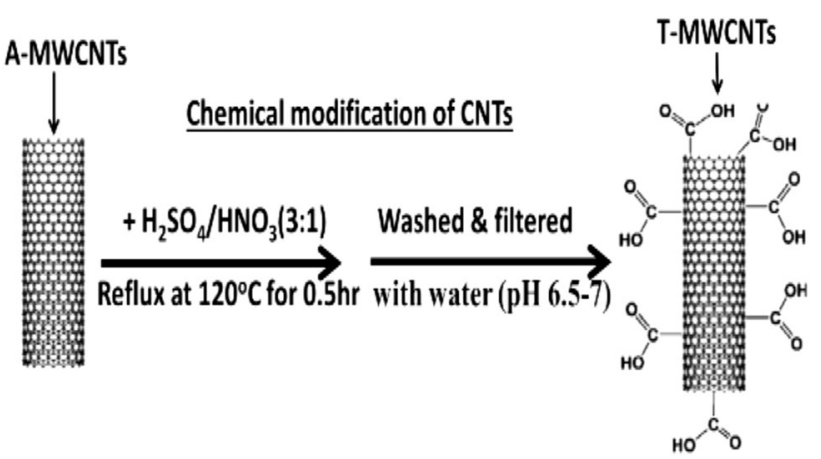

Fig. 1 Schematic representation of the acid treatment of A-MWCNTs

voltage of $10-20 \mathrm{kV}$. To obtain samples for SEM, liquid nitrogen was used to cryogenically freeze them for $5 \mathrm{~min}$. This is followed by fracturing of the samples. Composite samples were gold coated using an Edwards S150B sputter coater. TEM (Philips CM200) was used at an accelerating voltage of $200 \mathrm{kV}$. For sample preparation; diamond blade was used to cut slices of an approximately $50 \mathrm{~nm}$ thick from the core of the samples. Before that, samples were embedded into epoxy resin for slices purpose using an ultra-microtome (Leica EM UC6). In addition, CNTs were also mixed with ethanol, sonicated in an ultrasonic bath at room temperature for about $30 \mathrm{~min}$ to separate the agglomerated particles. A few drops of this suspension were dropped onto a copper grid using a micropipette. The grid was then left to dry in a fume cupboard to evaporate the ethanol.

\section{Electrical conductivity and percolation threshold measurements}

Electrical conductivity $(\sigma)$ at room temperature was measured using an impedance spectroscopy (NumetriQ PSM1735). It is also useful device for the determination of percolation threshold values $(\Phi)$. Samples $(\sim 10 \times 10 \times$ $1 \mathrm{~mm}^{3}$ ) were cut, polished, and coated using sliver paint to reduce the contact resistance. Resistance of PET and its nanocomposites was measured in a range of $1 \times 10^{-6}$ $10 \times 10^{-6} \mathrm{~Hz}$ at $1 \mathrm{~V}$ as an amplitude voltage.

\section{Thermal stability measurements}

Thermo-gravimetric analysis (TGA) was used to study the thermal stability of PET and its nanocomposites by measuring mass changes during heating as a function of temperature under a controlled atmosphere. Thermal stabilities were evaluated by determining temperature at $0.05(5 \%)$ weight loss $\left(T_{5} \%\right)$. The instrument used for TGA Q-500 TA Instruments in nitrogen and air atmospheres $(60 \mathrm{ml} /$ min). Samples $(\approx 6-7 \mathrm{mg}$ ) were scanned from room temperature to $700{ }^{\circ} \mathrm{C}$ at a heating rate of $10{ }^{\circ} \mathrm{C} / \mathrm{min}$.

\section{Tensile test measurements}

Dumbbell shape specimens for tensile testing were prepared using injection-moulding machine. The tensile testing was performed using Instron instrument of model 4301 at room temperature and crosshead speed of $5 \mathrm{~mm} / \mathrm{min}$ by following the ASTM D638 standard. The average of five test results was reported as a final value of tensile properties, including tensile modulus, strength, and elongation at break.

\section{Results and discussions}

\section{Morphology}

Figure 2a shows an entangled network arrangement that is typical of as A- MWCNTs. In contrast, the acid treatment of the A-MWCNTs (Fig. 2b) caused them to be less entangled. In addition, acid treatment usually shortens length and diameter of CNTs $[16,17]$.

The typical entangled nature of A-MWCNT is quite visible also from the TEM image (Fig. 3a). On the contrary, less entanglement is seen after acid treatment (Fig. 3b), resulting in an improved dispersion and distribution. Furthermore, at some locations catalyst, particles can be seen on the surface of the A-MWCNTs (black dots), as shown in Fig. 3a. Similar morphology has been reported in the literature $[16,17]$. The interesting aspect is that these particles were disappeared after acid treatments, as shown in Fig. 3b.

One of the favored features of acid treatment is that it attaches some hydroxyl and carboxyl functional groups to the walls of CNTs $[2,15,16]$. The number of these groups on the surface of A-MWCNTs depends on the acid treatment conditions, such as temperature, time, and oxidizing agents [8]. It is expected that these functional groups may improve interaction with the PET matrix. To confirm the presence of such functional groups, FTIR was conducted, as shown in Fig. 4. 

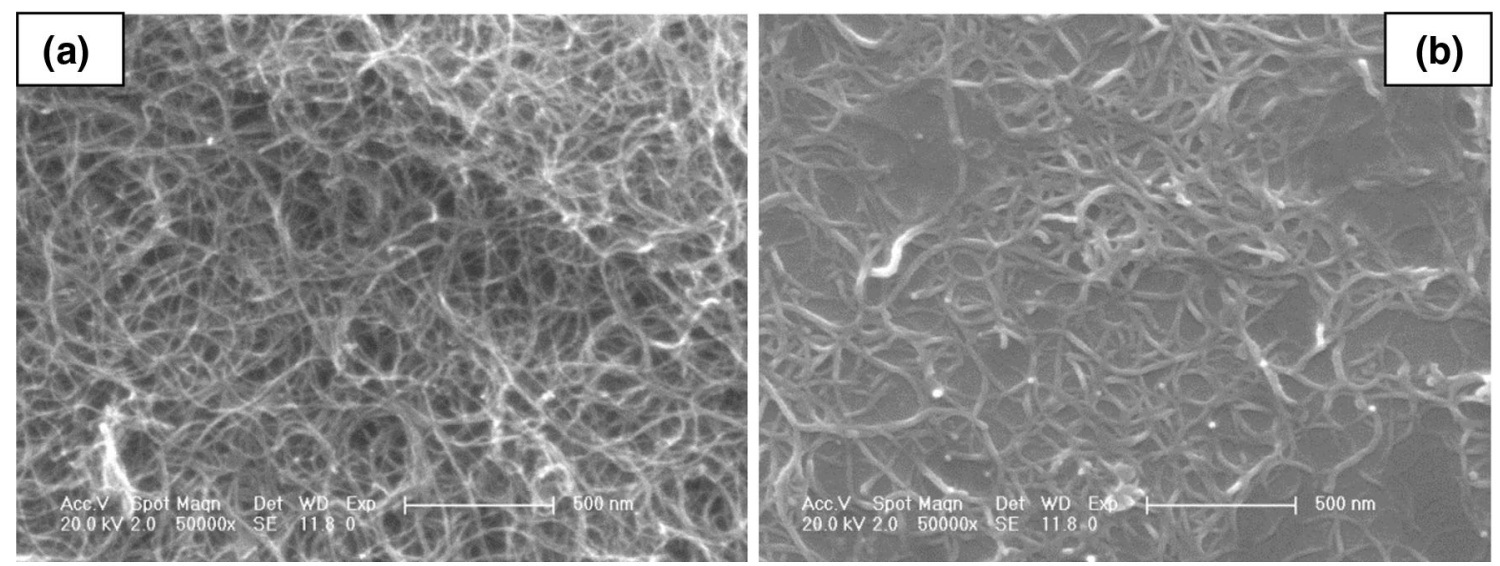

Fig. 2 SEM images; a A-MWCNTs and b T-MWCNTs
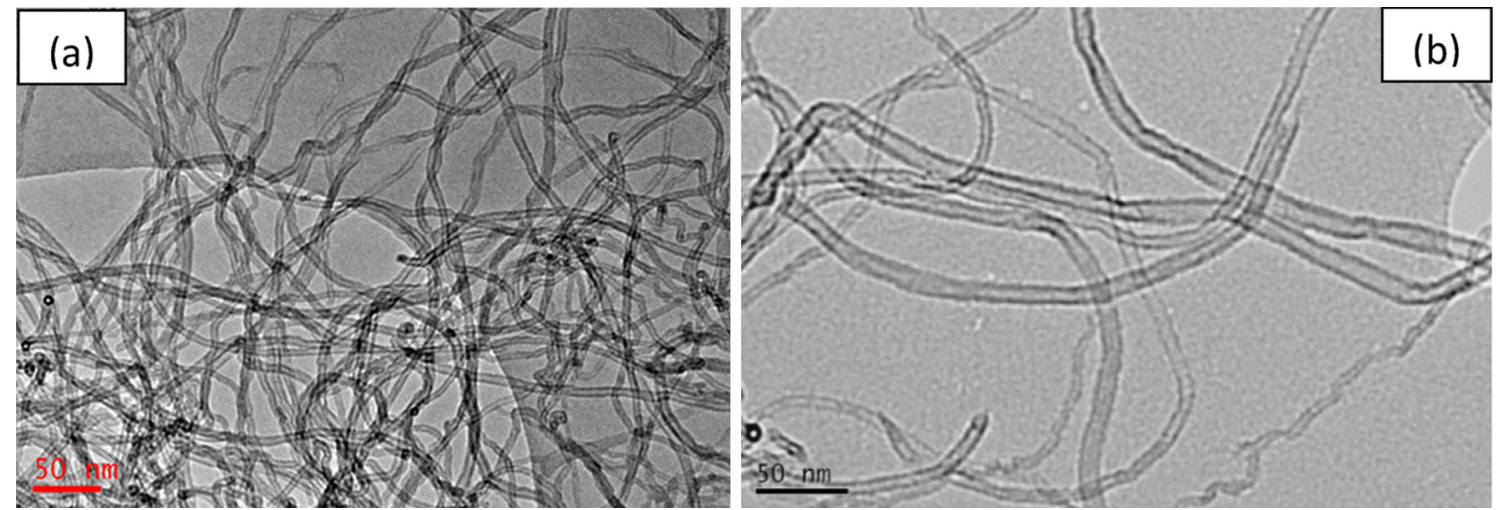

Fig. 3 TEM images; a A-MWCNT and b T-MWCNTs

The spectrum of the T-MWCNTs shows two strong peaks in the ranges of $3200-3600$ and $1600-1750 \mathrm{~cm}^{-1}$ that are characteristic of hydroxyl $(-\mathrm{OH})$ and carboxyl ($\mathrm{COOH})$ functional groups, respectively [15, 17]. This indicates the successful modification obtained in this study. According to the literature, the peak in the range $\sim 1710-1730 \mathrm{~cm}^{-1}$ is due to the stretching vibration of the $\mathrm{C}=\mathrm{O}$ groups in $-\mathrm{COOH}[15,18]$. Whereas in another study, the stretching vibration mode of the $\mathrm{C}=\mathrm{O}$ group found in the range of $1690-1660 \mathrm{~cm}^{-1}$. Wavenumber, at which peak appears, depends on the acid treatment time, e.g., Zhang et al. [18] found that peaks at $\sim 1735$ firstly but when acid treatment time was increased, the peaks shifted from $\sim 1737$ to $1720 \mathrm{~cm}^{-1}$.

The fracture surface (or the mid/or center of samples or cross section) was analyzed by SEM throughout this study. Micrographs of such fractured surfaces of the nanocomposites at $0.35 \mathrm{wt} \% \mathrm{CNTs}$ are shown in Fig. 5. In addition, based on the comparative analysis of samples without CNTs and with CNTs incorporation (previous literature [19]), the bright spots in the images appear are presumably CNTs, while the dark background is the PET matrix.

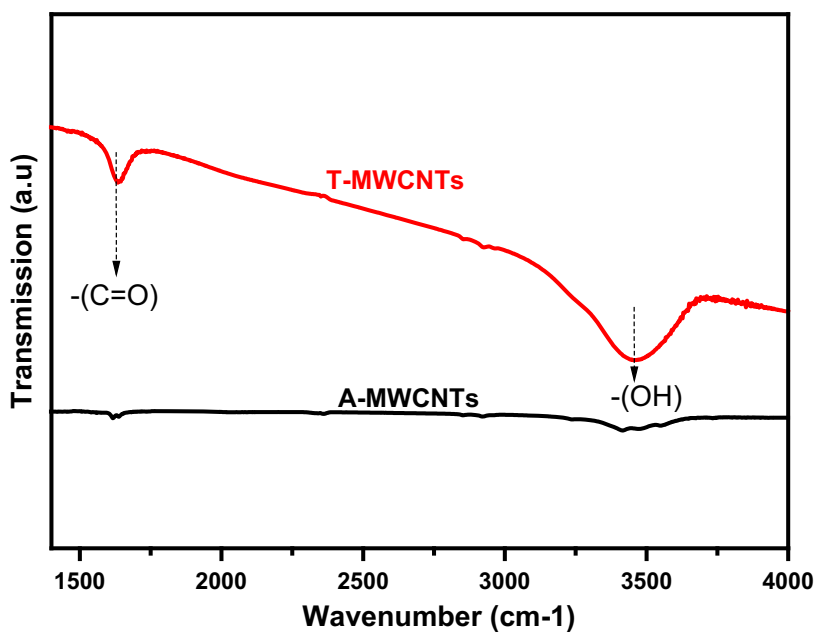

Fig. 4 FTIR spectra of A-MWCNTs and T-MWCNTs

A-MWCNTs show several bright spots (Fig. 5a), while in the case of T-MWCNTs, these are more embedded into the matrix, as shown in Fig. 5b. This indicates a better matrixfiller adhesion and in addition to good particle distribution. 
Similarly, Fig. 6 shows the TEM images of PET/AMWCNT and PET/T-MWCNTs nanocomposites at $0.35 \mathrm{wt} \%$ loading. The agglomeration and poor distribution are clearly noticed for PET/A-MWCNT as compared to PET/T-MWCNTs nanocomposites.

Comparable SEM observations were made for PET/ MWCNT nanocomposites by Santoro et al. [19] who concluded that a good dispersion has been achieved at $\sim 0.25 \mathrm{wt} \%$, followed by the agglomeration of CNTs. Similar observations were made by Zaman et al. [3] who reported improved dispersion, filler-matrix adhesion, and distribution of acid-treated MWCNTs in PET matrix.

\section{Electrical conductivity and percolation threshold values}

The real and imaginary parts of the complex impedance were obtained as a function of frequencies using impedance spectroscopy measurements. In this work, the values of conductivity at $10 \mathrm{~Hz}$ have been chosen. This is due to fact that at low frequencies, insulator-conductor transitions can only be noticed [20]. Usually, values for the conductivities were determined from the real part only using Eq. (1) $[12,21,22]$ :

$\sigma=\frac{L}{R A}$

where $\sigma$ is an electrical conductivity $(\mathrm{S} / \mathrm{m}), L$ is the distance between the electrodes $(\mathrm{m}), A$ is the cross-sectional area $\left(\mathrm{m}^{2}\right)$, and $R$ is the measured electrical resistance $(\Omega)$.

Figure $7 \mathrm{a}, \mathrm{b}$ shows the values of $\sigma$ of the nanocomposites as a function of CNTs (A-MWCNTs and T-MWCNTs) loadings (at room temperature and $10 \mathrm{kHz}$ ). It is clear that the PET/A-MWCNTs nanocomposite shows an excellent electrical conductivity and lower percolation thresholds value $(\sim 0.35 \mathrm{wt} \%)$ in comparison with PET/TMWCNTs counterpart.
Moreover, the PET/A-MWCNTs nanocomposites show a sharp transition from insulator behavior to conductive one, i.e., conductivity increased from $\sim 5.5 \times 10^{-9}$ to $\sim 10^{-4} \mathrm{~S} / \mathrm{m}$, as the loading increased from $\sim 0.25$ to $0.5 \mathrm{wt} \%$ of CNTs. Therefore, $\Phi_{c}$ occurs to be between 0.25 and $0.5 \mathrm{wt} \%$ of A-MWCNTs for the nanocomposites investigated in this study. It is clear also from this figure that there is a significant increase in $\sigma$ above $0.25 \mathrm{wt} \%$, where the adding only of an additional $0.1 \mathrm{wt} \%$ of A-MWCNTs (at $0.35 \mathrm{wt} \%$ ) increases the $\sigma$ by two orders of magnitude. Moreover, the $\sigma$ of $\sim 10^{-4} \mathrm{~S} / \mathrm{m}$ was obtained at $0.5 \mathrm{wt} \%$ of A-MWCNT that is higher than the value $\left(10^{-6} \mathrm{~S} / \mathrm{m}\right)$ which considered being necessary to avoid an electrostatic charging of polymer matrix.

Furthermore, to characterize insulator-conductor transitions of composites reinforced with conductive fillers, percolation theory is applied. This will facilitate the determination of percolation threshold and dimensions of conductive network in polymer matrices. According to the percolation theory, $\sigma$ of the composites is known by Eq. (2) $[12,21,22]$.

$\sigma=\sigma_{o}\left(\Phi-\Phi_{c}\right)^{t}, \quad$ for $\Phi>\Phi_{c}$

where $\sigma$ is proportionality constant, $\Phi_{c}$ is the percolation threshold value (vol.\%), $\Phi$ is the conductive filler content (vol.\%), and $t$ refers to the dimensionality of the system (geometry of the conductive path into the composites). In fact, the density of the CNTs is often an approximate value rather than real one. Thus, weight fractions have been used for determining the $\Phi_{c}$ in several published studies $[12,21,22]$. The determination of $\Phi_{c}$ in this study will be in the expression of weight fractions as well.

The best-fit data to the percolation threshold model [Eq. (2)] were obtained at the value of $0.33 \mathrm{wt} \%$ A-MWCNTs for $\Phi_{c}$ of PET/A-MWCNTs nanocomposites, as shown in the insert graph in Fig. 7a. On the other hand, the PET/T-MWCNTs nanocomposites had similar
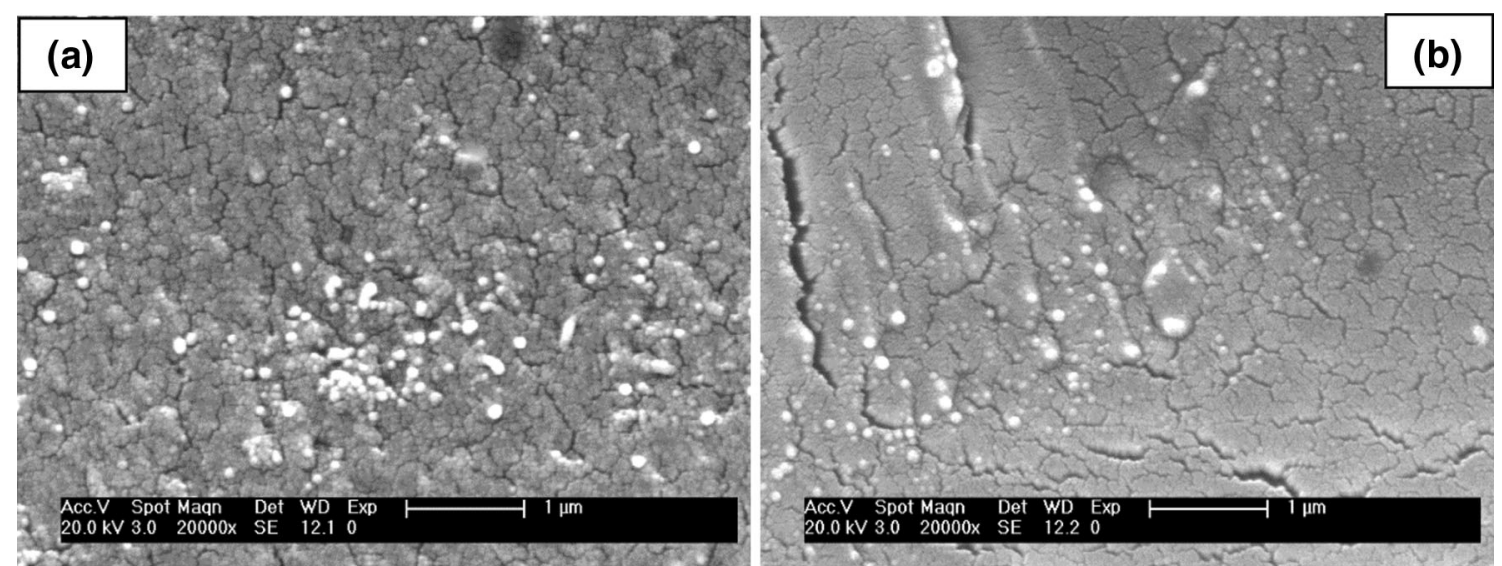

Fig. 5 SEM images of fractured surfaces of composites at $0.35 \mathrm{wt} \%$ CNTs loadings; a PET/A-MWCNTs and b PET/T-MWCNTs 

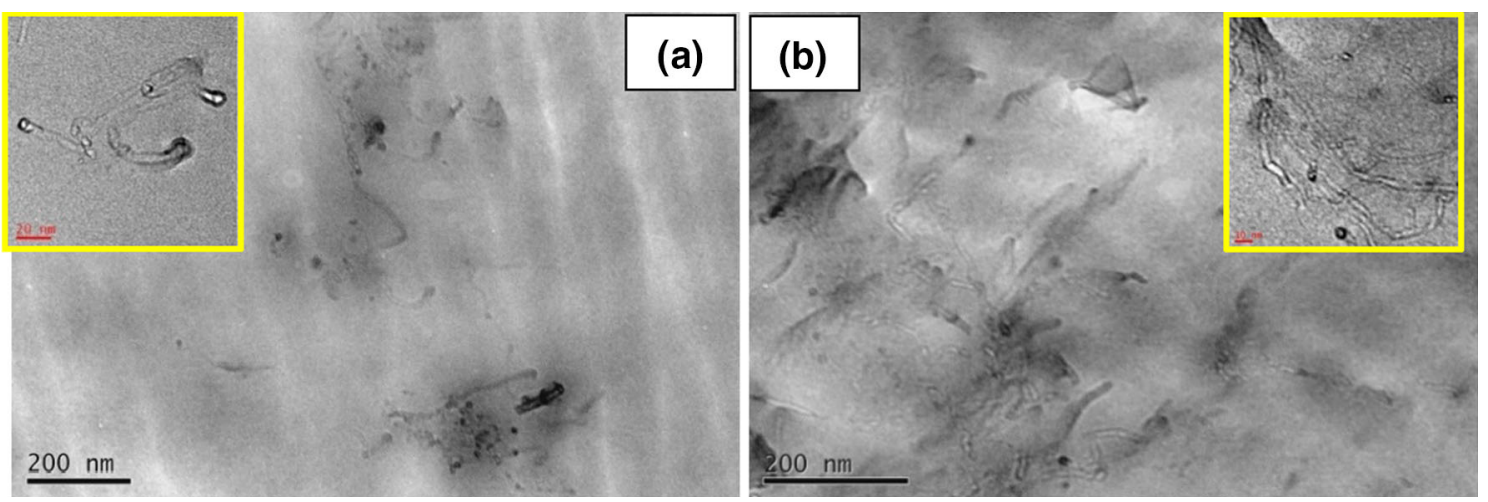

Fig. 6 TEM images; a PET/A-MWCNT and b PET/T-MWCNT nanocomposites at $0.35 \mathrm{wt} \%$. The inset images show magnified CNTs in the PET matrix
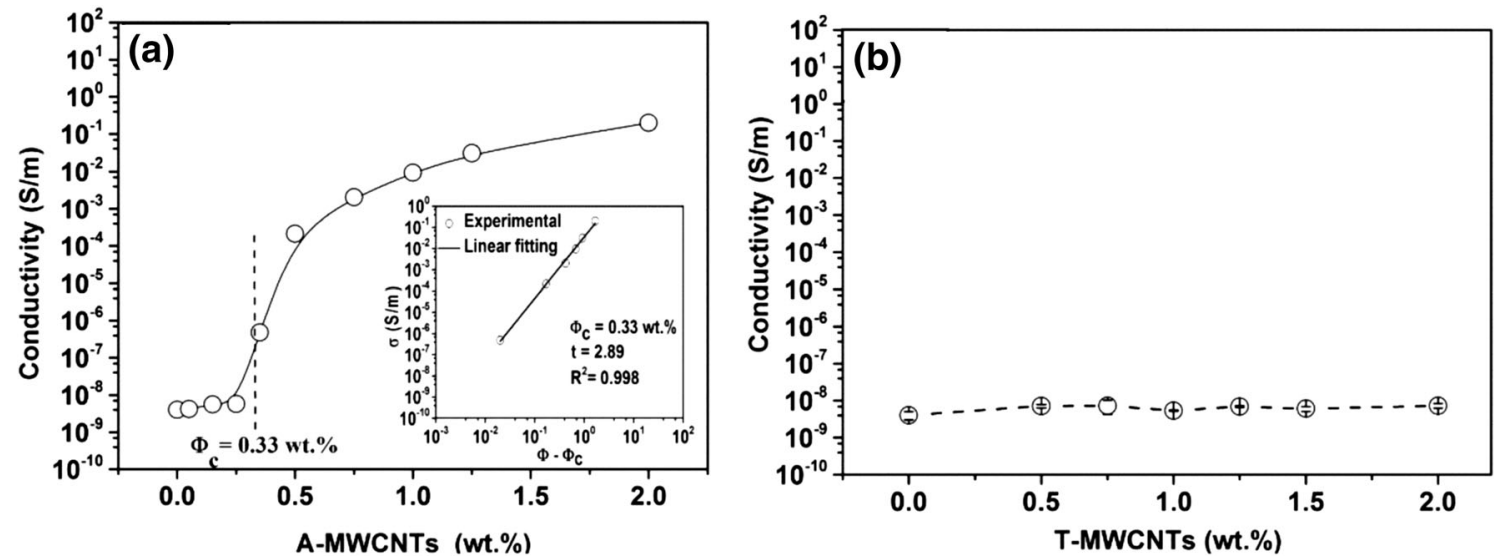

Fig. 7 Electrical conductivities of composites; a PET/A-MWCNTs and b PET/T-MWCNTs as a function of wt\% of CNTs. The inset plot is log $\sigma$ versus $\log \left(\Phi-\Phi_{c}\right)$ to assess the PT values

conductivity values to that of the pure PET. Therefore, percolation threshold was not observed within the T-MWCNTs loading used in this study. Thus, further investigation into the electrical properties of these nanocomposites above $2 \mathrm{wt} \%$ T-MWCNTs is suggested. This behavior could be attributed to shortening of the tube lengths of A-MWCNTs after acid treatment and improved compatibility to PET, as a result good dispersion and uniform distribution (as seen in SEM/TEM images). Therefore, this hinders the formation of conductive network through the matrix. In addition, the attachment of functional groups on CNTs walls reduces electrical conductivity of the nanocomposites. Several authors reported observation of low composites conductivities because of acid treatment [23-25]. They ascribed this performance to the formation of functional groups and defects sites on the surface of the A-MWCNTs after modification process using acid treatment.

According to the literature, the lowest $\Phi_{c}$ for PET/AMWCNTs nanocomposites was reported at $0.06 \mathrm{wt} \%$ by Logikis et al. who used an in situ polymerization method to prepare samples [26]. Whereas same authors reported $\Phi_{c}$ at $0.2 \mathrm{wt} \%$ for the same nanocomposite when made by melt compounding. These authors have also investigated the effect of functionalized MWCNTs on the electrical conductivity. They reported much lower $\sigma$ for composites containing functionalized CNTs. On the other hand, the highest value of $\Phi_{c}$ is found to be $0.9 \mathrm{wt} \%$ MWCNTs for such nanocomposites using the solution method [16].

\section{Thermal stability}

Figures 8 and 9 show the TGA data for composites reinforced with A-MWCNTs and T-MWCNTs in nitrogen and air atmospheres, respectively. Their $T_{5} \%$ values are presented in Tables 2 and 3, respectively. It appears that the presence A-MWCNTs improves the thermal stabilities of PET matrix in both environments (air and nitrogen). However, PET/T-MWCNTs nanocomposites showed an enhancement of thermal stabilities only in nitrogen atmosphere, i.e., higher than PET/A-MWCNTs counterpart did. 
For example, at $0.1 \mathrm{wt} \%$ loading in nitrogen atmosphere, the $T_{5} \%$ of PET/A-MWCNTs and PET/TMWCNTs is higher than pure PET by 5 and $11^{\circ} \mathrm{C}$, respectively. Particularly, this could be due to the stronger interfacial attraction between the carboxylic groups ($\mathrm{COOH})$ on the T-MWCNTs and the ester groups $(-\mathrm{C}=\mathrm{O})$ on the PET matrix owing to hydrogen bonding. Furthermore, A-MWCNTs can also lead to the stabilization of PET and may limit thermal motion of its molecules [4, 27].

Moreover, comparatively PET/T-MWCNT nanocomposites exhibit lower thermal stability than pure PET when heated in the air, as shown in Fig. $9 \mathrm{~b}$ and Table 3. Bikiaris et al. reported the thermal stability of isotactic polypropylene nanocomposites containing T-MWCNTs in the air and nitrogen atmospheres using different times of acid treatments [28].

The authors concluded that as the time of acid treatment increases, the onset temperature of thermo-oxidative decreases, which lowers thermal stability of the nanocomposites.

\section{Tensile results}

Figure 10 shows the stress-strain curves for PET and PET/ A-MWNTs nanocomposites. The values of modulus $(E)$, strength $\left(\sigma_{u}\right)$, and elongation at break $\left(\varepsilon_{u}\right)$ are presented in Table 4.

These results exhibit significant improvements of $E$ from $\sim 1073 \mathrm{MPa}$ for pure PET to $\sim 1303 \mathrm{MPa}$ for nanocomposites containing $2 \mathrm{wt} \%$ A-MWCNT $(21.5 \%)$. This improvements could be due to the high aspect ratio, strength, and modulus of CNTs that agrees to studies reviewed elsewhere [29].

Figure 11 compares the values of $E$ obtained from published study to the present data. The previous study that conducted by Santoro et al. [19] showed a sharp increase in $E$ values at 0.1 and $0.2 \mathrm{wt} \%$ MWCNTs, thereafter leveling off. A similar trend has been observed in the present study; however, the $E$ values in the previous study are much higher than ones obtained presently, although similar meltcompounding conditions was used for the nanocomposite preparations. This could be due to premixing of CNTs and PET by cryogenic milling before melt compounding in their study; hence, it could have resulted in good dispersion.

The values of $\sigma_{u}$ and $\varepsilon_{u}$ decline with increasing A-MWCNTs content. Values of $\sigma_{u}$ reduced from $46 \mathrm{MPa}$ for neat PET to $25 \mathrm{MPa}$ for nanocomposites containing up to $2 \mathrm{wt} \%$. A-MWCNTs. In addition, the elongation at break showed a decrease from $6 \%$ for pure PET to $2 \%$ at $2 \mathrm{wt} \%$ A-MWCNT. This reduction is believed to be due to the failure initiated at the CNTs aggregates within the nanocomposites that results in lower strains and bulk stresses at failure. Such decline is usually attributed to the agglomeration of CNTs in the polymer matrix, as reported by Aalaei et al. [30] who reported a $50 \%$ reduction in $\sigma_{u}$ for PP/MWCNTs nanocomposites at $5 \mathrm{wt} \%$ CNTs. In contrast, Santoro et al. [19] observed improvements in both tensile strength and elastic modulus of PET/A-MWCNT nanocomposites by 26 and $25 \%$, respectively, at $0.25 \mathrm{wt} \%$ loading of CNTs. The authors also concluded that further loadings did not improve these tensile properties. The improvement in the mechanical properties in their study was suggested to be due to the good dispersion of A-MWCNTs into the PET matrix (Fig. 12).

Moreover, Zhu et al. [31] achieved a good dispersion of A-MWCNTs into PET matrix also at $<0.4 \mathrm{wt} \%$ of CNTs. Their results exhibited that Young's modulus and $\sigma_{u}$ improved by 25 and $15 \%$, respectively, at $0.4 \mathrm{wt} \%$. These improvements were followed by a slight drop in $\sigma_{u}$ at 0.6 and $0.8 \mathrm{wt} \%$ of MWCNT loading. A similar study conducted by Kim et al. [32] investigated the effect of A-MWCNTs loading on the mechanical properties of a PET matrix. The authors reported that $10 \%$ enhancement for both $\sigma_{u}$ and $E$ at $0.5 \mathrm{wt} \%$ CNTs. No significant improvement was reported with further loading of
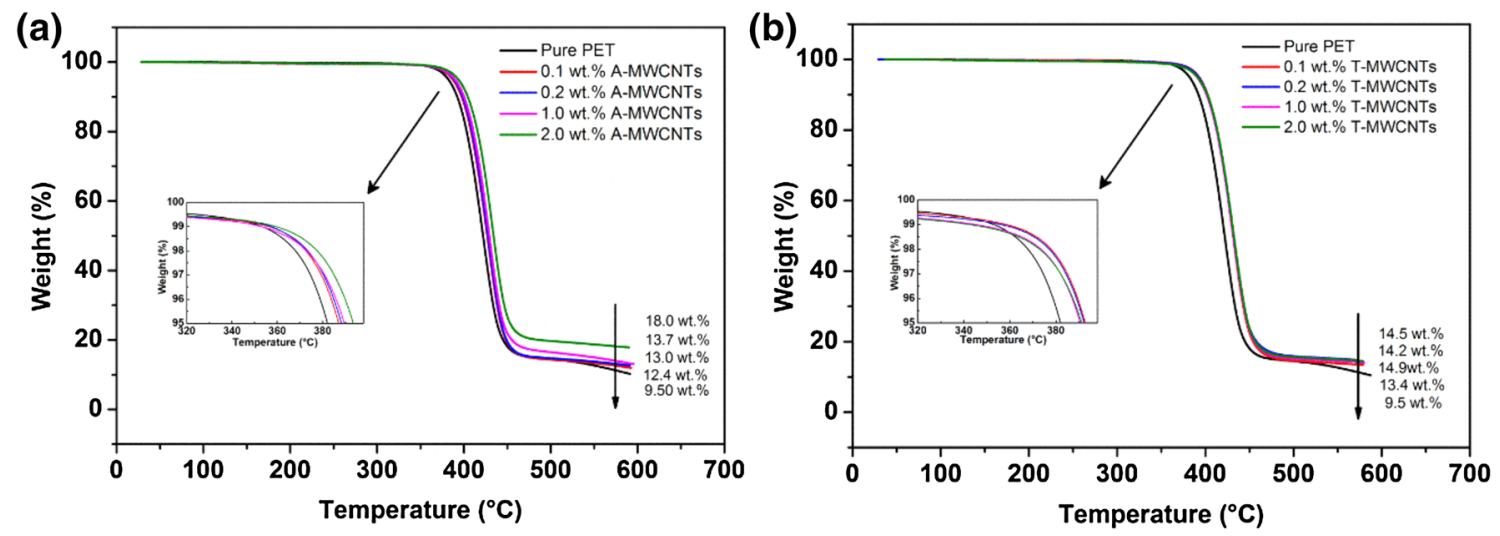

Fig. 8 TGA thermograms in nitrogen atmospheres; a PET/A-MWCNTs and b PET/T-MWCNTs

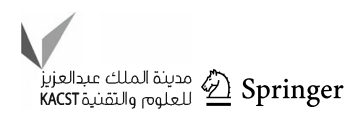



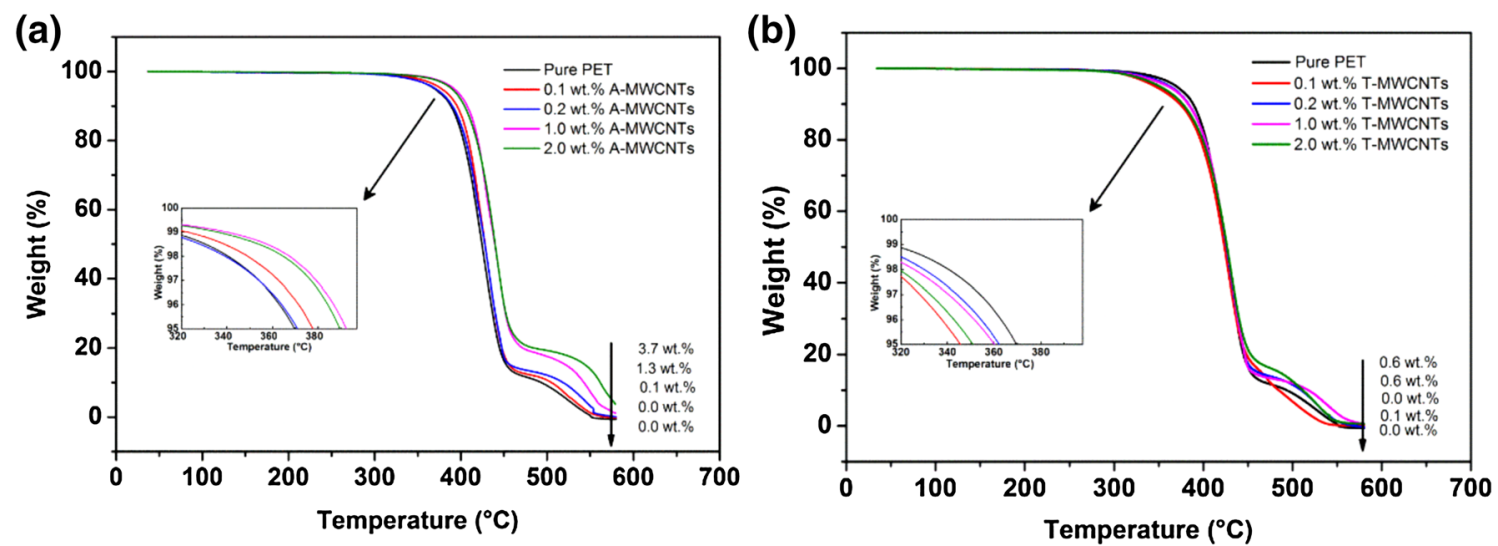

Fig. 9 TGA thermograms in air atmospheres; a PET/A-MWCNTs and b PET/T-MWCNTs

Table 2 Thermal degradation temperatures for PET/A-MWCNTs nanocomposites under nitrogen and air atmospheres

\begin{tabular}{lll}
\hline A-MWCNT (wt\%) & $\begin{array}{l}\mathrm{N}_{2} \\
T_{5} \%\left({ }^{\circ} \mathrm{C}\right)\end{array}$ & $\begin{array}{l}\text { Air } \\
T_{5} \%\left({ }^{\circ} \mathrm{C}\right)\end{array}$ \\
\hline 0.0 & $382.3 \pm 1.4$ & $370.1 \pm 1.0$ \\
0.1 & $387.3 \pm 2.2$ & $376.9 \pm 0.8$ \\
0.2 & $388.8 \pm 2.3$ & $372.0 \pm 0.9$ \\
1.0 & $389.8 \pm 2.7$ & $392.5 \pm 2.2$ \\
2.0 & $392.8 \pm 1.5$ & $390.0 \pm 1.5$ \\
\hline
\end{tabular}

Table 3 Thermal degradation temperatures for PET/T-MWCNTs nanocomposites under nitrogen and air atmospheres

\begin{tabular}{lll}
\hline T-MWCNT (wt $\%)$ & $\mathrm{N}_{2}$ & Air \\
& $T_{5} \%\left({ }^{\circ} \mathrm{C}\right)$ & $T_{5} \%\left({ }^{\circ} \mathrm{C}\right)$ \\
\hline 0.0 & $382.3 \pm 1.4$ & $370.1 \pm 1.0$ \\
0.1 & $392.8 \pm 0.2$ & $346.5 \pm 0.8$ \\
0.2 & $392.7 \pm 2.3$ & $360.9 \pm 1.3$ \\
1.0 & $390.7 \pm 0.9$ & $356.5 \pm 6.4$ \\
2.0 & $391.3 \pm 0.9$ & $351.3 \pm 2.0$ \\
\hline
\end{tabular}

A-MWCNTs, which they attributed to the tendency of CNTs to bundle up and aggregate together at higher loading. This results in low efficiency of load transfer between the PET and A-MWCNTs.

Improvements in the values of $E$ have also been reported for PET nanocomposites containing T-MWCNTs by Zaman et al. [3], as shown in Fig. 13. Interestingly, the trend shown in this figure is similar in both studies. For example, the value of $E$ at $0.1 \mathrm{wt} \%$ in the present study is identical to the $E$ value obtained by Zaman et al. who reported similar improvements in modulus but at higher loadings of CNTs, i.e., $0.3 \mathrm{wt} \%$. This indicates uniform dispersion at lower loadings of CNTs. Upon further filler addition, the sharp improvement in $E$ values in both the studies was observed and thereafter leveled off.
Table 5 shows no significant change in $\sigma_{u}$ up to $0.2 \mathrm{wt} \%$ of T-MWCNTs. This can be attributed to a better dispersion state when compared with A-MWCNTs. However, significant reductions in $\sigma_{u}$ up to $\sim 44$ and $50 \%$ were observed for the composites containing 1 and $2 \mathrm{wt} \%$ T-MWCNT, respectively. This is probably due to poor dispersion and distribution, as agglomeration was noticeable at higher loading. Similar behavior has been reported for PS nanocomposites containing T-MWCNTs [21].

These results seem to be in contrast with ones obtained by Gupta et al. [33], who reported an increase in the values of $\sigma_{u}$ for poly (trimethylene terephthalate) (PTT)-CNTs nanocomposites upon the addition of treated MWCNTs. This variation in results could be attributed to different fabrication methods and conditions of acid-treatment process. For example, Gupta [33] used sonication of CNTs before acid treatment. On the other hand, Amr et al. [21] utilized only nitric acid for treatments of CNTs.

Furthermore, the $\varepsilon_{u}$ values also decreased upon incorporation of T-MWCNTs in the present study, indicating that nanocomposites became less ductile and brittle compared to the PET matrix. This because increased in modulus of the composites. Gupta et al. [33] and Meng et al. [34] have reported reduction in $\varepsilon_{u}$ values for PTT and Polyamide6 (PA6) nanocomposites containing treated MWCNTs. Moreover, Pat et al. [35] stated that the PET nanocomposites containing treated MWCNTs were extremely brittle outstanding to higher crystallinity of polymer matrix.

On contrary, Zaman et al. [3] reported an enhancement in both the $\sigma_{u}$ and $\varepsilon_{u}$ values of nanocomposites upon increasing the amount of T-MWCNTs up to $0.5 \mathrm{wt} \%$ of filler (they used the same grade as in the present study); this was followed by a decrease due to aggregation issue. It should be noted that they modified CNTs in a mixture of concentrated nitric and sulfuric acids at room temperature for $24 \mathrm{~h}$. It has resulted in an improvement of interfacial 


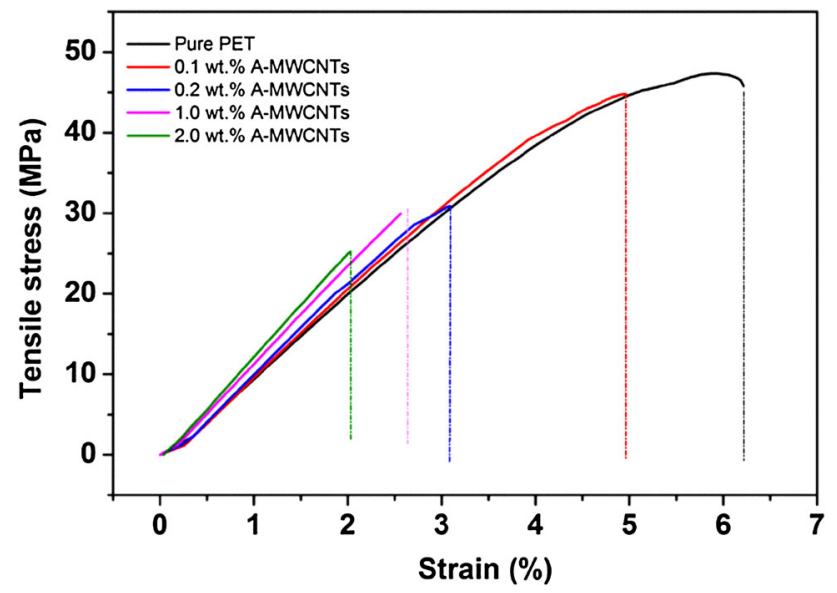

Fig. 10 Typical stress-strain curves of the PET/A-MWCNT nanocomposites

Table 4 Tensile properties of the PET/A-MWCNT nanocomposites

\begin{tabular}{llll}
\hline $\begin{array}{l}\text { A-MWCNT } \\
(\mathrm{wt} \%)\end{array}$ & $\begin{array}{l}\text { Tensile } \\
\text { modulus }(\mathrm{MPa})\end{array}$ & $\begin{array}{l}\text { Tensile strength } \\
(\mathrm{MPa})\end{array}$ & $\begin{array}{l}\text { Elongation } \\
\text { at break }(\%)\end{array}$ \\
\hline 0.0 & $1073.3 \pm 15.7$ & $45.8 \pm 2.3$ & $6.3 \pm 1.9$ \\
0.1 & $1124.0 \pm 24.7$ & $44.8 \pm 5.0$ & $4.9 \pm 0.9$ \\
0.2 & $1182.3 \pm 52.1$ & $32.0 \pm 2.5$ & $3.1 \pm 0.2$ \\
1.0 & $1252.6 \pm 31.3$ & $30.0 \pm 3.8$ & $2.6 \pm 0.3$ \\
2.0 & $1302.7 \pm 30.0$ & $25.2 \pm 4.1$ & $2.0 \pm 0.3$ \\
\hline
\end{tabular}

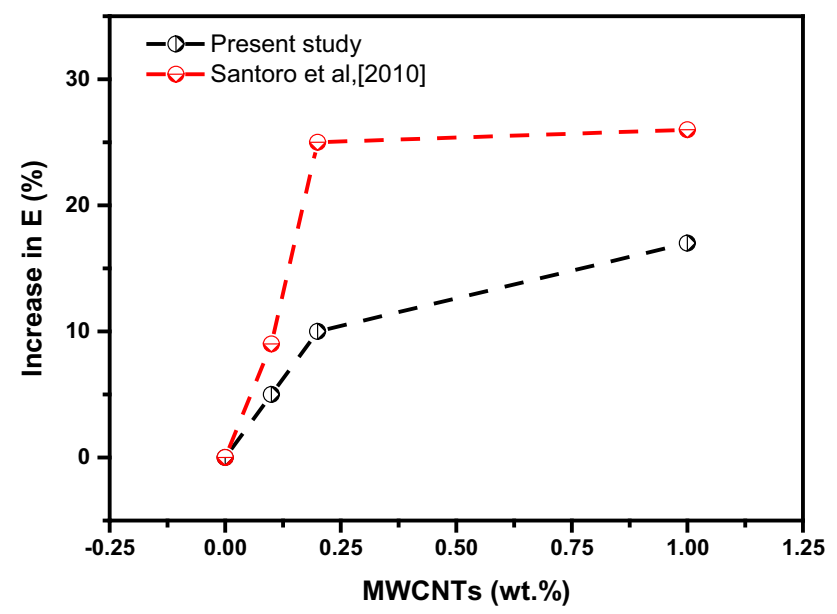

Fig. 11 Comparison of $E$ data from Santoro et al. [19] and the present study

interactions between the matrix and the filler. Therefore, an effective load transfer was noticed in their study. However, it was reported [8] that the mechanical properties of composites containing treated MWCNTs depend on the treatment temperature, time, and the composition of the acid mixture or oxidizing agents. This displays that severe

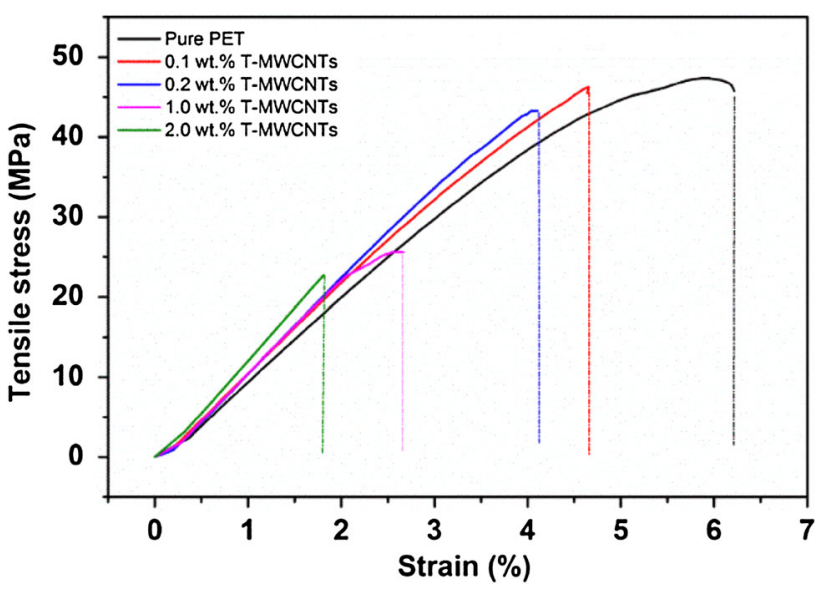

Fig. 12 Typical stress-strain curves of the PET/T-MWCNT nanocomposites

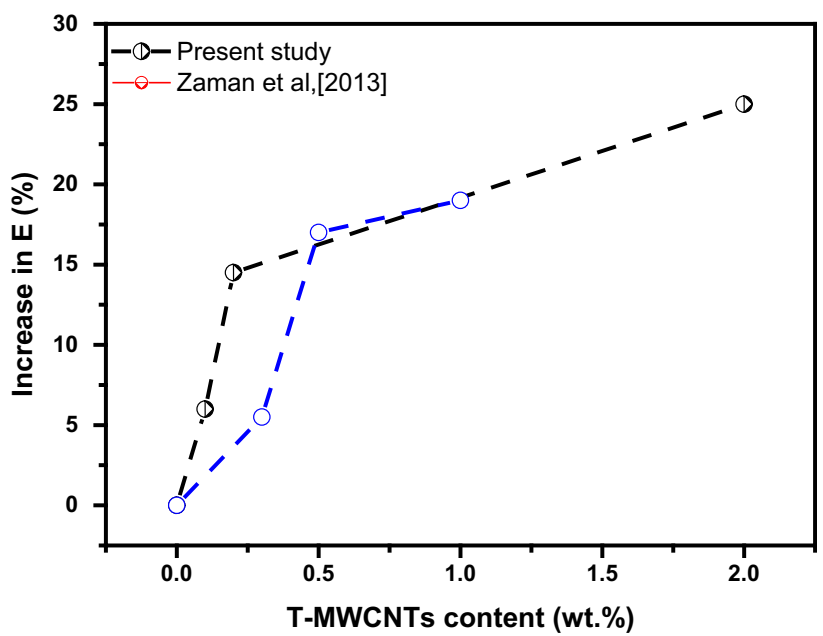

Fig. 13 Comparison of $E$ data from Zaman et al. [3] and the present study

Table 5 Tensile properties of the PET/T-MWCNT nanocomposites

\begin{tabular}{llll}
\hline $\begin{array}{l}\text { T-MWCNT } \\
(\mathrm{wt} \%)\end{array}$ & $\begin{array}{l}\text { Tensile } \\
\text { modulus }(\mathrm{MPa})\end{array}$ & $\begin{array}{l}\text { Tensile } \\
\text { strength }(\mathrm{MPa})\end{array}$ & $\begin{array}{l}\text { Elongation } \\
\text { at break }(\%)\end{array}$ \\
\hline 0.0 & $1073.3 \pm 15.7$ & $45.8 \pm 2.3$ & $6.3 \pm 1.9$ \\
0.1 & $1141.9 \pm 17.3$ & $46.3 \pm 2.9$ & $4.7 \pm 0.5$ \\
0.2 & $1230.0 \pm 34.0$ & $43.3 \pm 2.9$ & $4.1 \pm 0.3$ \\
1.0 & $1222.5 \pm 105$ & $25.6 \pm 6.0$ & $2.7 \pm 0.8$ \\
2.0 & $1343.2 \pm 13.8$ & $22.7 \pm 1.8$ & $1.8 \pm 0.1$ \\
\hline
\end{tabular}

modification lowers the mechanical properties of the final nanocomposites. Bikiaris et al. [28] concluded that the size of agglomeration was decreased by increasing the time of acid treatment which can improve mechanical properties.

It is crucial to compare the tensile properties of both A-MWCNTs and T-MWCNTs based on PET 
nanocomposites that investigated in the present study. Interestingly, the values of $E$ for the PET/T-MWCNTs nanocomposites (see Fig. 12 and Table 5) were noted to be higher than that of PET/A-MWCNTs nanocomposites at all identical loadings of CNTs, whereas values of $\sigma_{u}$ at lower concentration of CNTs, i.e., 0.1 and $0.2 \mathrm{wt} \%$ T-MWCNT were higher than that obtained at same loading of A-MWCNTs. Such improvements can be attributed to an improved level of dispersion, interfacial interaction, and adhesion between the CNTs and the PET matrix in addition uniform distribution of T-MWCNTs.

\section{Conclusions}

Two set of CNTs were prepared, i.e., A-MWCNTs (as received) and T-MWCNTs (acid treated). These CNTs were incorporated into PET matrix using melt-compounding method. The purpose of functionalization treatment to A-MWCNTs was to reduce entanglement and to attach functional groups that were confirmed by FTIR. Therefore, the focus of this study was to investigate the effect of modification treatment on resultant properties of the nanocomposites. The electrical, thermal, morphological, and tensile properties were examined as a function of CNTs weight fraction.

Morphological examination of both A-MWCNTs and T-MWCNTs was carried out. It was found that acid treatment facilitates the reduction of the entanglement of CNTs. In addition, functional groups (carboxyl and hydroxyl) were found in T-MWCNTs owing to acid treatment.

The addition of small loading $(\sim 0.35 \mathrm{wt} \%$ A-MWCNTs) showed two orders of magnitude higher electrical conductivity than that of pure PET polymer. Whereas, at the same loading of T-MWCNTs into PET, no improvement in an electrical conductivity was noticed. Electrical conductivity of PET/T-MWCNTs nanocomposite and pure PET was similar. In addition, no percolation threshold was also found even over the T-MWCNTs up to $2 \mathrm{wt} \%$ of T-MWCNTs. However, the addition of A-MWCNTs showed a percolation threshold at $0.33 \mathrm{wt} \%$ of CNTs. Presumably, this is because of disruption of inherent electrical conductivity and reduction in aspect ratio of CNTs caused by acid treatment. Nevertheless, T-MWCNTs exhibited better dispersion and distribution resulting in reduced CNTs-CNTs interactions and hence the absence of conductive network structures. In addition, acid treatment resulted in higher tensile modulus and strength than that of PET/A-MWCNT counterpart, particularly at low loadings.

Moreover, an improved thermal stability of PET in both the air and nitrogen atmospheres was observed upon incorporation of A-MWCNTs. On contrary, an enhanced thermal stability was also observed in nitrogen atmosphere only when T-MWCNTs were incorporated in PET matrix. In comparison, PET/T-MWCNTs nanocomposites exhibited higher thermal stability than that of PET/A-MWCNTs counterpart in nitrogen atmosphere. Nevertheless, the modification of CNTs showed a negative effect on the thermal stability of PET/T-MWCNTs in air atmosphere.

Acknowledgments I would like to thank King Abdullaziz City for Science and Technology (KACST) for their generous funding throughout this project.

Open Access This article is distributed under the terms of the Creative Commons Attribution 4.0 International License (http:// creativecommons.org/licenses/by/4.0/), which permits unrestricted use, distribution, and reproduction in any medium, provided you give appropriate credit to the original author(s) and the source, provide a link to the Creative Commons license, and indicate if changes were made.

\section{References}

1. Szeluga Urszula, Kumanek Bogumiła, Trzebicka Barbara (2015) Synergy in hybrid polymer/nanocarbon composites. A review. Compos Part A 73:204-231

2. Harris PJF (2009) Carbon nanotube science: synthesis, properties and applications. Cambridge University Press, USA

3. Zaman HU, Hun PD, Khan RA, Yoon K-B (2013) Effect of multi-walled carbon nanotubes on morphology, mechanical and thermal properties of poly (ethylene terephthalate) nanocomposites. Fuller Nanotub Carbon Nanostruct 21:701-711

4. Young Kim J, Choi HJ, Kang CS, Kim SH (2010) Influence of modified carbon nanotube on physical properties and crystallization behavior of poly (ethylene terephthalate) nanocomposite. Polym Compos 31:858-869

5. Sengupta R, Bhattacharya M, Bandyopadhyay S, Bhowmick AK (2011) A review on the mechanical and electrical properties of graphite and modified graphite reinforced polymer composites. Prog Polym Sci 36:638-670

6. Gao Xiang, Isayev Avraam I, Yi Chao (2016) Ultrasonic treatment of polycarbonate/carbon nanotubes composites. Polymer 84:209-222

7. Xin F, Li L, Chan SH, Zhao J (2012) Influences of carbon fillers on electrical conductivity and crystallinity of polyethylene terephthalate. J Compos Mater 46:1091-1099

8. Sahoo NG, Rana S, Cho JW, Li L, Chan SH (2010) Polymer nanocomposites based on functionalized carbon nanotubes. Prog Polym Sci 35:837-867

9. Brydson J (1999) Plastic materials, 7th edn. Butterworth-Heinemann Linacre House, Oxford

10. Harper CA Petrie EM (2003) Plastics materials and processes: a concise encyclopedia. Wiley, USA

11. Li M, Jeong YG (2011) Poly (ethylene terephthalate)/exfoliated graphite nanocomposites with improved thermal stability, mechanical and electrical properties. Compos Part A Appl Sci Manuf 42:560-566

12. Sandler J, Shaffer M, Prasse T, Bauhofer W, Schulte K, Windle A (1999) Development of a dispersion process for carbon nanotubes in an epoxy matrix and the resulting electrical properties. Polymer 40:5967-5971

13. Ma PC, Siddiqui NA, Marom G, Kim J-K (2010) Dispersion and functionalization of carbon nanotubes for polymer-based nanocomposites: a review. Compos Part A Appl Sci Manuf 41:1345-1367 
14. Paul S, Kim D-W (2009) Preparation and characterization of highly conductive transparent films with single-walled carbon nanotubes for flexible display applications. Carbon 47:2436-2441

15. Verdejo R, Lamoriniere S, Cottam B, Bismarck A, Shaffer M (2007) Removal of oxidation debris from multi-walled carbon nanotubes. Chem Commun 43:513-515

16. Hu G, Zhao C, Zhang S, Yang M, Wang Z (2006) Low percolation thresholds of electrical conductivity and rheology in poly (ethylene terephthalate) through the networks of multi-walled carbon nanotubes. Polymer 47:480-488

17. Amr IT, Al-Amer A, Al-Harthi M, Girei SA, Sougrat R, Atieh MA (2011) Effect of acid treated carbon nanotubes on mechanical, rheological and thermal properties of polystyrene nanocomposites. Compos Part B Eng 42:1554-1561

18. Zhang J, Zou H, Qing Q, Yang Y, Li Q, Liu Z, Guo X, Du Z (2003) Effect of chemical oxidation on the structure of singlewalled carbon nanotubes. J Phys Chem B 107:3712-3718

19. Santoro G, Gómez MA, Marco C, Ellis G (2010) A solvent-free dispersion method for the preparation of PET/MWCNT composites. Macromol Mater Eng 295:652-659

20. Římská Z, Křesálek V, Špaček J (2002) AC conductivity of carbon fiber-polymermatrix. Polym Compos 23:95-103

21. Sandler J, Kirk J, Kinloch I, Shaffer M, Windle A (2003) Ultralow electrical percolation threshold in carbon-nanotube-epoxy composites. Polymer 44:5893-5899

22. Bauhofer Wolfgang, Kovacs JZ (2009) A review and analysis of electrical percolation in carbon nanotube polymer composites. Compos Sci Technol 69:1486-1498

23. Yesil Sertan, Bayram Goknur (2011) Effect of carbon nanotube purification on the electrical and mechanical properties of poly (ethylene terephthalate) composites with carbon nanotubes in low concentration. J Appl Polym Sci 119:3360-3371

24. Yesil S, Bayram Goknur (2011) Poly (ethylene terephthalate)/carbon nanotube composites prepared with chemically treated carbon nanotubes. Polym Eng Sci 51:1286-1300

25. Rajendran Royan NR, Sulong AB, Sahari J, Suherman H (2013) Effect of acidand ultraviolet/ozonolysis-treated MWCNTs on the electrical and mechanical properties of epoxy nanocomposites as bipolar plate applications. J Nanomater 2013:717459. doi:10. 1155/2013/717459

26. Logakis E, Pissis P, Pospiech D, Korwitz A, Krause B, Reuter U, Pötschke P (2010) Low electrical percolation threshold in poly (ethylene terephthalate)/multi-walled carbon nanotube nanocomposites. Eur Polym J 46:928-936

27. Vassiliou AA, Chrissafis K, Bikiaris DN (2010) Thermal degradation kinetics of in situ prepared PET nanocomposites with acidtreated multi-walled carbon nanotubes. J Therm Anal Calorim 100:1063-1071

28. Bikiaris D, Vassiliou A, Chrissafis K, Paraskevopoulos KM, Jannakoudakis A, Docoslis A (2008) Effect of acid treated multiwalled carbon nanotubes on the mechanical, permeability, thermal properties and thermooxidative stability of isotactic polypropylene. Polym Degrad Stab 93:952-967

29. Spitalsky Z, Tasis D, Papagelis K, Galiotis C (2010) Carbon nanotube-polymer composites: chemistry, processing, mechanical and electrical properties. Prog Polym Sci 35:357-401

30. Aalaie J, Rahmatpour A, Maghami S (2007) Preparation and characterization of linear low density polyethylene/carbon nanotube nanocomposites. J Macromol Sci Part B Phys 46:877-889

31. Zhu Z, Wang R, Dong Z, Huang X, Zhang D (2011) Morphology, crystallization, and mechanical properties of poly (ethylene terephthalate)/multiwalled carbon nanotubes composites. J Appl Polym Sci 120:3460-3468

32. Young Kim J, Park HS, Kim SH (2007) Multiwall-carbon-nanotube-reinforced poly (ethylene terephthalate) nanocomposites by melt compounding. J Appl Polym sci 103:1450-1457

33. Gupta A, Choudhary Veena (2013) Thermal and mechanical properties of poly (trimethyelene terephthalate)/acid-treated multiwalled carbon nanotube composites. J Mater Sci 48:7063-7070

34. Meng H, Sui G, Fang P, Yang R (2008) Effects of acid-and diamine-modified MWNTs on the mechanical properties and crystallization behavior of polyamide 6. Polymer 49:610-620

35. May-Pat A, Avilés F, Toro P, Yazdani Pedram P, Cauich Rodríguez J (2012) Mechanical properties of PET composites using multi-walled carbon nanotubes functionalized by inorganic and itaconic acids. Express Polym Lett 6(2):96-106 